\title{
The Relationship between International Student Library Use and Information Needs
}

\author{
Zhixian Yi
}

\begin{abstract}
This study examines how international student library use relates to their information needs and the factors influencing their information needs. The collected quantitative data were analyzed using descriptive statistics (percentages) and inferential statistics (ordinal regression). The regression analysis confirms that demographics, human capital, and library use variables play significant roles in predicting international student information needs. Demographic variables such as age, human capital data such as education level, databases, interlibrary loan, ejournals, library reserve, ready reference, online subject guides, browsing the Internet, email and print materials are significant predictors of international student information needs, but this study indicates that gender, library catalog, and remote access to the library offerings make no difference. The findings will help library directors, managers and librarians to reflect on the factors' influences and to use the results to break down international students into smaller groups and evaluate, develop and enhance services and resources to satisfy their increasing information needs.
\end{abstract}

\section{Introduction}

In the modern world, the rapid development of science and technology has entered a new era. Information technologies, especially the Internet, have brought about great changes in the working and learning environments. In 1993, the Massachusetts Board of Library Commissioners identified four key trends influencing the shape of future library services: globalization, the information explosion, electronic access of information and a growing need for lifelong learning and retraining (Massachusetts Board of Library Commissioners, 1993). Twenty years later, the trends are still current.

In the changing academic library settings, demands for high quality library resources and services from the patron communities are consistently increasing.

\section{Author}

Zhixian (George) Yi, Ph.D. is a Lecturer in the School of Information Studies at Charles Sturt University, Wagga Wagga, NSW, Australia.

Email: gyi@csu.edu.au 
With the increase in the enrollments of international students in American colleges and universities, there emerge diverse patron communities in the academic libraries. The academic libraries play a very important role in meeting patrons' increased information needs by providing more specialised resources and services.

A previous report of this study (Yi, 2007) showed that international students at Texas Woman's University (TWU) had their own information needs and use features. In the free-text responses, $75 \%$ of doctoral students, $58.1 \%$ of graduate students, and $38.9 \%$ of undergraduate students who participated in a previous study (Yi, 2007) responded that they needed the additional resources and services. They needed more textbooks and main books concerning courses. One surveyed respondent held the view that there was:

"Need for more textbooks and main books which are required for a course and are not present in the library so have to depend on interlibrary loan."

Another respondent reported:

"Need more numbers of nutrition textbooks. They are not available here but we (nutrition students) borrow those books from other places."

And yet another respondent needed:

"Course relevant information and previous book related to previous exams so that a student can get an idea of his/her future test paper pattern."

In terms of special programs and journals, they had additional needs. One respondent said:

"There are many things that a student can need. There should be a special program for English for international students. Our university does not have subscription of many journals."

Another respondent demanded that "More journals [sic] should be added therefore there is no need to go and search in other places for important information." A further respondent reported:

"Need more journals that have online text available. Also there are a lot of journals issues missing related to my field - Occupational Therapy. Not many textbooks are available related to my field for students to refer to."

At the same time, international students used a variety of library resources and services frequently. However, it was not known whether their library use impacted on their information needs.

The university library is the main place for the international students to study and obtain academic resources and services. Whether international students have library anxiety, how they utilize library resources and services, what problems and difficulties they encounter, and what information needs, seeking, and use characteristics they possess have been research areas. However, there is little research on the correlation or relationship between international student library use and information needs. This article describes fresh analyses of data collected in the study described in Yi (2007). These analyses address two research questions: 
- How does international student library use relate to their information needs?

- What factors influence their information needs?

Factors influencing their information needs include: (1) demographics (age and gender); (2) human capital (education level); and (3) library use variables. According to Frank \& Bernanke (2007), human capital is:

"an amalgam of factors such as education, experience, training, intelligence, energy, work habits, trustworthiness, and initiative that affect the value of a worker's marginal product."

Education level was chosen because 62 percent of the TWU international students were graduate students. Those with different education levels may have various information needs.

The findings will help library directors, managers and librarians to reflect on the factors' influences, to evaluate, develop and enhance the available resources and services, to satisfy international student future information needs, and faculty to improve teaching efficiency for international students.

\section{Literature review}

Statistics demonstrate that the number of students studying overseas has increased steadily over the past six decades (Institute of International Education, 2012a). For example, trend data from Open Doors shows that the number of international students in higher education institutions in the United States (U.S.) in 1954-55 was $1.4 \%$ of the total enrollment. In 2011-12, international students comprised $3.7 \%$ of total higher education enrollments in U.S. institutions (Institute of International Education, 2012b). Enrolment data from Texas Woman's University (TWU) indicates that international students averaged $3.19 \%$ of total enrolments between 2002 and 2011 (Texas Woman's University, 2012). The majority of international students at TWU were from countries where English is not the first language (Texas Woman's University, 2012).

Similar trends in international student numbers have occurred globally. For example, in 2011, 20\% of higher education student enrolments in Australia were international students (Australian Bureau of Statistics, 2011). Office of Economic Development (2011) (OECD) education statistics indicate that "In 2009, almost 3.7 million tertiary students were enrolled outside their country of citizenship."

The OECD report also emphasises that the majority of foreign students enrolled in tertiary institutions outside their own country are from countries where English is not the first language, predominantly Asian countries.

Clearly, international students comprise an important and growing element of the user populations of academic libraries around the world. Not unexpectedly, there is a growing body of library and information studies research on issues relating to international students and academic libraries as information specialists strive to understand and meet the needs of all patrons.

A snapshot of some of the literature emanating from Australia, New Zealand, North America, and Asia on library use and information experiences of 
international students follows. The review covers studies that focus on problem identification as well as studies on strategies for mitigating those problems.

An early study in 1984 by Goudy and Moushey surveyed academic librarians at 44 U.S. higher education institutions to gauge the extent to which libraries were developing special library programs and services to meet the needs of the increasing number of international students. The results showed that most respondents considered it appropriate to develop specific programs to assist international students in their information seeking and use. Respondents also identified a number of key concerns for international students, including problems with English communication and lack of confidence in their communication skills, which impeded their use of reference services (Goudy and Moushey, 1984, 224).

Questions about library skills in relation to English language proficiency were also the subject of a study by Bilal (1989) who surveyed international students studying at the Florida State University Center for Intensive English Studies in 1987. The study found that levels of English language proficiency, awareness of information research skill and concepts, and self-sufficiency and confidence were major factors in students' ability to comprehend the library skills programs (Bilal, 1989).

Ziming Liu (1993) interviewed 54 students from developing countries at the University of California, Berkley, to examine factors influencing their effective use of academic libraries. He found that key problem areas were a lack of English proficiency and lack of familiarity with facilities and services available in American libraries. Issues with ethical use of information were also problematic as students were unfamiliar with referencing styles and requirements.

Mengxiong Liu and Redfern (1997) conducted a survey of students at San Jose University, California to explore information seeking and use behaviors and communication patterns of multicultural students. Theire findings indicate that English language proficiency, residency time in the U. S., and awareness and willingness to use reference services were the main factors influencing efficiency and effectiveness of information seeking (Liu and Redfern, 1997). "A fear of asking stupid questions", "a belief that their English is not good enough", "inability to understand answers well", and "a lack of familiarity with the library reference desk" were the main anxieties exhibited by Asian students when using the academic libraries (Liu and Redfern, 1997).

Onwuegbuzie and Jiao (1997) conducted a discriminant analysis to examine how frequently and why native English-speaking students and international students used academic libraries and which group had the highest library anxiety level. Their study, based on Mellon's grounded theory of library anxiety (Mellon, 1986), used two instruments: a "Demographic Information Form", developed specifically for the study, and the "Library Anxiety Scale", developed by Bostick (1992). The findings showed international students used the libraries more frequently for a wider range of reasons, and spent more time in the libraries than did their English speaking peers. Onwuegbuzie and Jiao's $(1997,265)$ study also showed that international students had lower levels of anxiety relating to knowledge about the library, but they had higher levels of library anxiety relating to perceived barriers 
such as communication difficulties with library staff, perceptions of inadequacy using the library, and mechanical barriers such as computer usage.

These studies are only a small, but significant reflection of some of the older literature on international students' information seeking and use behaviours, and reflect concerns about the barriers faced by international students in the identification and satisfaction of their information needs.

More recent literature reflects many of the same concerns. Carlile (2007) summarised library anxiety research in the context of academic reference services, noting that many students have library anxiety about their lack of knowledge about how to use the library efficiently and effectively.

Cultural barriers continue to be a common area of research in relation to international students and academic libraries. Ademodi (2011) explored the literature on international students' use of reference services in academic libraries, noting that research studies indicate that international students are often reluctant to approach reference librarians because they do not want to be a nuisance, and are not aware of the reference librarian's role. His study considers how reference services for international students could be improved, based on Association for College and Research Libraries (ACRL) standards for services to students.

In a study of multilingual graduate students at Florida State University, Dagli (2004) examined whether there was a relationship between their perceptions of culture and their specific information needs. The findings indicated that their information needs were:

"affected by cultural elements such as language, level of education, geographic region, communication and interaction styles, age, cultural proximity to culture of host country, and length of stay in [the] host country"

(Dagli, 2004, 173)

Liu and Winn (2009) examined the information seeking behaviors of 12 Chinese graduate students at the University of Windsor, Ontario, Canada. The findings indicated that language and cultural issues still posed significant barriers to the students. Although the students expressed confidence in their information searching skills, the study showed that many were not aware of the myriad library resources available in North American academic libraries. Nor were they sufficiently aware of legal and ethical issues relating to information use and citation requirements. Most also had difficulties with spoken English and were reluctant to seek clarification of library systems (Liu and Winn, 2009, 571-572).

In another Canadian study, Morrissey and Given (2006) conducted in-depth interviews with eight Chinese graduate students at the University of Alberta to examine their experiences using the academic libraries. The findings highlighted a number of key challenges for the students and for academic libraries serving international students including English language proficiency, information literacy skills, lack of awareness of the roles of academic and reference librarians, and the need for targeted training on library technologies.

Issues relating to cultural differences in information literacy awareness are also reflected in Bruce and Hughes (2010). Their study, which was based on a 
relational model of information literacy, examined the experiences of 25 international students using online information resources at two Australian universities. The findings showed that despite having relatively sophisticated digital skills when using Internet applications, their effective use of online library resources was limited by a lack of familiarity with journal databases and other resources. They also showed "limited critical or strategic engagement with online resources" and were "unfamiliar with the academic style and cultural references" (Bruce and Hughes, 2010, A5).

Problems with library-based information technologies were also the focus of research by Mehra and Bilal (2007). Their research examined the priority information needs, technological barriers, and information seeking behaviors of ten international students at the University of Tennessee. The findings indicate that the international students faced considerable challenges using library-based technologies, conducting effective search strategies and dealing with information overload. These challenges were compounded by cultural and linguistic considerations (Mehra and Bilal, 2007, 8).

Recent studies of information seeking behaviors have also been conducted by Safahieh (2007) and Martin et al. (2009). Safahieh's study of international students at three public universities in Malaysia explored their information needs and searching behaviors. The findings demonstrated that a number of barriers impeded students' ability to meet their information needs. Key factors included language barriers, a reluctance to seek assistance from librarians, and lack of familiarity with the library systems and services. The results also showed some gender differences in the ability to meet information needs, with females indicating greater difficulties meeting their information needs than males (Safahieh, 2007, 90-94).

Martin and others exploratory study of the information seeking behaviors of international and U. S. students at two university campuses in Nebraska found no differences in searching skills between the two groups. This finding was contrary to expectations given previously reported research (Martin et al., 2009, 10). The study also found that international students used the library more frequently than U. S. students but were more likely to need assistance on basic library skills (Martin et al., 2009, 11).

A number of recent studies have also considered ways in which academic librarians can adopt a more proactive approach to reducing cultural and linguistic barriers that seem to be significant impediments in the information seeking and use behaviors of international students. These, and some of the studies above, reflect an emerging trend to move beyond problem identification and definition to finding solutions.

Amsberry $(2009,17)$ explores the impact of communication on international students' effective use of library facilities and services and argues that library staff would benefit from targeted training in cross-cultural communication, particularly listening to accented oral communication, and improved awareness of cultural values and norms of body language and learning styles. Koeningstein $(2012,571)$ considers a range of strategies librarians can use to alleviate the culture shock and library anxieties of international students, pointing to issues of improved targeted 
training in ethical use of information, references services and research techniques. Peacock (2009) echoes those sentiments and suggests that librarians can do more to help the social acclimation of international students, including more proactive engagement with international student groups and identifying the best way to prepare and present information on library services and facilities.

Sacker et al. (2008) reiterate that academic librarians need to liaise more closely with international students to determine their preferences for library services and communication. In a survey of international students at La Trobe University, Melbourne, Australia, they found that international students required information at the point of need and had a preference for face-to-face contact and web guides rather than printed instructions (Sacker et al., 2008, 43,46, 47).

$\mathrm{Mu}$ (2007) argues that academic libraries need to develop new strategies for marketing academic library resources to international students. Surveys of students at the University of Canterbury, New Zealand, found that many students were not aware of the services available to them. The findings highlight the need for librarians to develop programs that reflect different learning styles and transcend cultural and linguistic challenges (Mu, 2007, 571).

Hughes (2010) also looked at strategies for meeting the needs of international students, but from the students' perspectives. Qualitative research at two Australian universities surveyed 17 international students in relation to library use experiences and perceptions of librarians and information literacy training programs. The findings mirrored results from other studies demonstrating that international students face challenges using libraries, due to a lack of familiarity with the library resources and facilities available to them. However, unlike some earlier studies that suggested students were reluctant to approach librarians, most of the students in this study reported positive engagements with librarians (Hughes, 2010, 84-85). Hughes suggests a range of mutually beneficial strategies to enhance the information seeking experiences of international students.

Puente et al. (2009) explored ways to enhance the information experience of ethnic minority groups at the University of Tennessee. Their survey of students, faculty and staff indicate that "there are misconceptions about how and why students from underrepresented groups utilize library services at the University of Tennessee" (Puente et al., 2009, 39). Most respondents indicated they did not experience difficulty finding and accessing material in the library, and were positive about new outreach programs being developed by staff.

The studies briefly reported above reflect a pattern of research themes identified by Peters (2010) in a comprehensive review of the literature. She notes that the 1980s generated a considerable body of anecdotal and scholarly research on international students and academic libraries, although much of the early research focused on librarians' perceptions of students' needs (Peters, 2010, 4). However, from the 1990s there has been an increasing focus on issues relating to, inter alia, technological skills, bibliographic instruction, information literacy and information seeking behaviours. More recent student-focused research has followed a number of recurring themes: culture shock, communications and language proficiency issues, differences in cultural norms and expectations, differences in learning styles, differences between libraries and library services in 
the country of origin and the host country, and library anxiety (Peters, 2010, 513). Library-focused research tends to examine issues relating to library orientation services for foreign students, bibliographic instruction, information literacy considerations, and reference services (Peters, 2010, 13-29).

Despite the wealth of research into the challenges faced by international students studying in countries other than their country of origin, strategies for assisting in their information and library experiences, there is still very little published on the relationship between international student library use and information needs. This paper, a further analysis of data explored in Yi (2007), aims to fill this gap.

\section{Study framework and hypothesis development}

The framework for this study is to test the relationships between international student information needs and demographics, human capital, and library use variables. International student preferences in information needs may depend on many factors. In this study, the variables considered focus on demographics, human capital and library use variables.

International students who were older, females or with a higher level of education were more likely than their counterparts to respond that they needed more information for or about: improving English proficiency; solving academic problems for classes; improving library skills; software applications usage; and/or periodicals in their native languages.

According to Liu and Redfern (1997), "Those students who used the library more frequently were more successful in locating needed information in the library than those who seldom or never used the library." This suggests that frequency of library use can impact users' ability to locate needed information. The more familiar with library resources and service tools the multicultural students are, the more successful they are in obtaining what they need. It is hypothesized that those who more frequently used online catalog, databases, remote access, interlibrary loan, e-journals, library reserve, ready reference, online subject guides, the Internet, email, or printed materials were more likely than their counterparts to respond that they needed more information for or about improving English proficiency; solving academic problems for classes; improving library skills; software applications usage; and/or periodicals in their native languages.

\section{Data and analytical strategies}

The data were collected from an email survey that was sent to 85 international students who were randomly selected from all the valid email addresses offered by the International Education Office in 2004. Sixty-one completed and returned surveys. The response rate was about $71.8 \%$. The survey questions tracked students' experiences with library use and information needs.

The dependent variables are five kinds of information needed by international students: information for improving English proficiency; information for solving academic problems for classes; information for improving library skills, information concerning software applications usage, and/or information on periodicals in their native languages (Yi, 2007, 673). 
The independent variables are (1) demographics (gender and age); (2) human capital (education level); and (3) library use variables (online catalog, databases, remote access to the library offerings, interlibrary loan, e-journals, library reserve, ready reference, online subject guides, browsing the Internet, email, and print materials (Yi, 2007, 668, 671, 672).

The collected quantitative data were first analyzed using descriptive statistics (percentage, medians and ranges). Then, the technique used to analyze the data was ordinal regression because the dependent variables were ordinal. Ordinal regression is usually used to determine the relationships between a dependent variable with multiple categories and many independent variables.

The survey sample size of this study was relatively small. The results may lack generalisability.

\section{Findings and discussion}

\subsection{Descriptive results}

Table 1 below shows the medians and ranges of the variables. The dependent variables are ordinal ones, ranked on a scale of 1-6 from "No need" to "Intense need". The "No Need" scale was not used in the analysis.

Gender was a dummy variable, represented by "Female" (83.6\% of respondents). The independent variable: "Female" was not included in Table 1 below. Age had five categories (17-20 years, 21-30 years, $31-40,41-50$ and $>50$ years). Three educational levels were noted, ranging from bachelors degree to doctorate. Library use variables were ordinal ones, ranked on a scale of 1-6 from "No use" to "Every day". The "No Use" scale was not used in the analysis. 
Table 1: Descriptive Statistics of Variables Used in the Analysis.

\begin{tabular}{|c|c|c|}
\hline Variables & Median & Range \\
\hline \multicolumn{3}{|l|}{ Dependent Variables } \\
\hline Information for improving English proficiency & 3 & 5 \\
\hline Information for solving academic problems for classes & 4 & 5 \\
\hline Information for improving library skills & 4 & 5 \\
\hline Information concerning software applications usage & 4 & 5 \\
\hline Information on periodicals in native languages & 2 & 5 \\
\hline \multicolumn{3}{|l|}{ Independent Variables } \\
\hline Education level & 2 & 2 \\
\hline Age & 2 & 3 \\
\hline Online catalog & 4 & 5 \\
\hline Databases & 4 & 5 \\
\hline Remote access to the library offerings & 2 & 5 \\
\hline Interlibrary loan & 2 & 4 \\
\hline E-journals & 3 & 5 \\
\hline Library reserve & 2 & 5 \\
\hline Ready reference & 3 & 5 \\
\hline Online subject guides & 3 & 5 \\
\hline Browsing the Internet & 5 & 5 \\
\hline Email & 5 & 5 \\
\hline Print materials & 5 & 5 \\
\hline
\end{tabular}

\subsection{Results of Ordinal Regression}

Ordinal regression is a sort of a regression analysis used to measure attitudes, views and effectiveness. A dependent variable is composed of many categories. The ordinal regression results of Tables 2 and 3 were generated using the software for the Statistical Package for the Social Sciences (SPSS).

Table 2 below reports the ordinal regression estimates (beta) that predicted the patterns of international student information needs. The results show that independent variables - education level and age - significantly impacted the outcome variables. The asterisks indicate the significance level of these results, with a single asterisk marking results significant to the 0.05 level (meaning the probability of the value occurring by chance was less than or equal to $5 \%$ ), a double asterisk marking results significant to the 0.01 level (meaning the probability of the value occurring by chance was less than or equal $1 \%$ ), and a triple asterisk marking results significant to the 0.001 level (meaning the probability of the value occurring by chance was less than or equal to $0.1 \%$ ).

Education level was detected to be positively and significantly associated with the probability of information need on the software applications usage. Those with higher education were more likely than their counterparts to respond that they needed information on software applications usage. This supports the first hypothesis. It implies that higher-level courses require students to have more 
experience and practice on software applications and that students should improve their ability to use software applications skills in their research. In responding to questions about what additional resources and services they needed, one respondent answered "access to audio visual software like windows media player or Java enabled programs at separate or guarded terminals for international students". The more often they use the software, the more information they might need. However, education level did not affect the respondents' other types of information needs.

Table 2: Ordinal Regression Estimates Predicting the International Student Attitudes towards Information Needs

\begin{tabular}{|c|c|c|c|c|c|}
\hline Predictors & $\begin{array}{c}\text { Improving } \\
\text { English } \\
\text { Proficiency } \\
\beta \\
\end{array}$ & $\begin{array}{l}\text { Solving } \\
\text { Academic } \\
\text { Problems } \\
\beta \\
\end{array}$ & $\begin{array}{l}\text { Improving } \\
\text { Library } \\
\text { Skills } \\
\quad \beta \\
\end{array}$ & $\begin{array}{l}\text { Software } \\
\text { Applications } \\
\text { Usage } \\
\beta \\
\end{array}$ & $\begin{array}{l}\text { Periodicals } \\
\text { in Native } \\
\text { Languages } \\
\beta \\
\end{array}$ \\
\hline \multirow[t]{2}{*}{ Threshold 1} & $5.434 * * *$ & .410 & .879 & $-9.710 * * *$ & $9.303 * * *$ \\
\hline & $(2.538)$ & $(-2.733)$ & $(2.838)$ & $(1.753)$ & $(2.444)$ \\
\hline \multirow[t]{2}{*}{ Threshold 2} & $8.010 * * *$ & 1.432 & 1.906 & $-8.094 * * *$ & $1.187 * * *$ \\
\hline & (2.319) & $(2.752)$ & $(2.844)$ & $(1.708)$ & $(2.396)$ \\
\hline \multirow[t]{2}{*}{ Threshold 3} & $0.104 * * *$ & 3.966 & 3.553 & $-6.440 * * *$ & $3.086^{* * * *}$ \\
\hline & $(2.259)$ & $(2.801)$ & $(2.886)$ & $(1.677)$ & $(2.403)$ \\
\hline \multirow[t]{2}{*}{ Threshold 4} & $1.763 * * *$ & $5.979 *$ & 5.078 & $-4.963 * * *$ & $5.510 * * *$ \\
\hline & $(2.279)$ & $(2.856)$ & $(2.944)$ & $(1.662)$ & $(2.583)$ \\
\hline \multirow[t]{2}{*}{ Education level } & .013 & .645 & .550 & $1.348^{*}$ & 1.501 \\
\hline & (1.051) & $(.653)$ & $(1.101)$ & $(.377)$ & $(1.132)$ \\
\hline \multirow[t]{2}{*}{ Age } & $-0.517 * *$ & $3.810 *$ & -1.003 & $-1.532 * * *$ & $0.032 * *$ \\
\hline & (1.006) & $(1.205)$ & $(1.434)$ & $(.567)$ & $(1.201)$ \\
\hline \multirow[t]{2}{*}{ Female } & -.939 & 262 & 1.410 & -.185 & 3.337 \\
\hline & (1.884) & $(.998)$ & $(1.122)$ & (1.004) & $(2.093)$ \\
\hline-2 log likelihood & 72 & 98 & 104 & 100 & 58 \\
\hline Model $\chi^{2}$ & 32 & 30 & 26 & 27 & 34 \\
\hline Pseudo R² & .643 & .532 & .486 & 507 & .711 \\
\hline 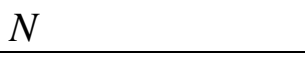 & 33 & 43 & 41 & 40 & 30 \\
\hline
\end{tabular}

There was a positive and significant relationship between age and information for solving academic problems and periodicals in native languages. Students who were older were more likely than their counterparts to respond that they needed information for solving academic problems and periodicals in native language. 
This is consistent with the first hypothesis and suggests that older students might encounter more academic difficulties. Their academic course requirements demanded these related information needs. In the library, they could read the latest information on their majors through available English periodicals, but they wanted to understand what research had been conducted in their fields in their own countries through reading through periodicals in their native languages. They might compare and contrast what they read in English and their native languages to accomplish assignments and projects and to perform creative research.

The relationships between age and information needs for improving English proficiency and software applications usage were negative and very significant. Older students were less likely than younger students to respond that they needed information for improving English proficiency and software applications usage. This does not support the first hypothesis. It suggests that either older students had better English proficiency than younger students or they did not require knowledge and skills about how to apply software in their studies and research.

In Table 3 below, the results demonstrate that there are many significant relationships between library use variables and information needs. Independent variables, such as databases, interlibrary loan, e-journals, library reserve, ready reference, online subject guides, browsing the Internet and email, significantly influenced the outcome variables.

The relationship between the use of databases and the need for information for solving academic problems was very significant and positive. Those who used databases more were more likely than their counterparts to respond that they needed information for solving academic problems. This supports the second hypothesis. It suggests that the database use aroused their interests in solving academic problems for classes and research. The more frequently they used databases, the more likely they were to need more related and updated information on how to use them. Returned questionnaires noted the need for additional resources such as "more databases for research articles - Nutrition, ... more databases added in library services, and more online music databases".

A negative and significant relationship between the use of interlibrary loan and the need for information for improving English proficiency and periodicals in native languages was detected. Those who used interlibrary loan more often were less likely than their counterparts to respond that they needed information for improving English proficiency and periodicals in native languages. This is not consistent with the hypothesis. It may indicate that the students have adequate library knowledge and skills and know how to get needed resources and services through interlibrary loan.

There was a negative and very significant relationship between the use of ejournals and the need for information for solving academic problems and software applications usage. Those who used e-journals more were less likely to respond that they needed information for solving academic problems and software applications usage. This might imply that their information needs in these two aspects were met in the library and they needed other kinds of library resources and services. 
Table 3: Ordinal Regression Estimates Predicting the International Student Attitudes towards Information Needs

\begin{tabular}{|c|c|c|c|c|c|}
\hline Predictors & $\begin{array}{c}\text { Improving } \\
\text { English } \\
\text { Proficiency } \\
\beta \\
\end{array}$ & $\begin{array}{c}\text { Solving } \\
\text { Academic } \\
\text { Problems } \\
\beta \\
\end{array}$ & $\begin{array}{l}\text { Improving } \\
\text { Library } \\
\text { Skills } \\
\beta \\
\end{array}$ & $\begin{array}{l}\text { Software } \\
\text { Applications } \\
\text { Usage } \\
\beta \\
\end{array}$ & $\begin{array}{l}\text { Periodicals } \\
\text { in Native } \\
\text { Languages } \\
\beta \\
\end{array}$ \\
\hline \multirow[t]{2}{*}{ Online catalog } & .436 & -.689 & -.749 & -.805 & .024 \\
\hline & $(.543)$ & $(.449)$ & $(.446)$ & $(.459)$ & $(.776)$ \\
\hline \multirow[t]{2}{*}{ Databases } & .370 & $2.000 * * *$ & .509 & .855 & -.381 \\
\hline & $(.574)$ & $(.606)$ & $(.558)$ & $(.570)$ & $(.732)$ \\
\hline \multirow[t]{2}{*}{$\begin{array}{l}\text { Remote access to } \\
\text { library offerings }\end{array}$} & -.123 & -.423 & .858 & .162 & 1.377 \\
\hline & $(.667)$ & $(.443)$ & $(.640)$ & $(.498)$ & $(.930)$ \\
\hline \multirow[t]{2}{*}{ Interlibrary loan } & $-1.242 *$ & .664 & .282 & .587 & $-1.703^{*}$ \\
\hline & $(.560)$ & $(.457)$ & $(.460)$ & $(.461)$ & $(.771)$ \\
\hline \multirow[t]{2}{*}{ E-journals } & -.622 & $-1.670 * * *$ & -.896 & $-1.412 * *$ & .910 \\
\hline & $(.585)$ & $(.523)$ & $(.517)$ & $(.532)$ & $(.809)$ \\
\hline \multirow[t]{2}{*}{ Library reserve } & .633 & $1.082 *$ & .011 & .547 & -.023 \\
\hline & $(.526)$ & $(.493)$ & $(.453)$ & .477 & $(.625)$ \\
\hline \multirow[t]{2}{*}{ Ready reference } & .021 & $-1.829 * *$ & -1.051 & $-1.838^{*}$ & -.342 \\
\hline & $(.684)$ & $(.661)$ & $(.672)$ & $(.752)$ & 1.024 \\
\hline \multirow[t]{2}{*}{ Online subject guides } & .121 & .231 & .794 & $.918 *$ & .219 \\
\hline & $(.485)$ & $(.372)$ & $(.509)$ & $(.451)$ & $(.546)$ \\
\hline \multicolumn{6}{|l|}{ Browsing the } \\
\hline Internet & $(1.062)$ & $(.479)$ & $(.503)$ & $(.469)$ & $(1.145)$ \\
\hline \multirow[t]{2}{*}{ Email } & $3.071^{* *}$ & $-1.127 *$ & .121 & -.169 & $3.613^{*}$ \\
\hline & (1.122) & $(.565)$ & $(.588)$ & $(.576)$ & (1.437) \\
\hline \multirow[t]{2}{*}{ Print materials } & -.250 & .758 & $1.080 *$ & .464 & $-1.979 * *$ \\
\hline & $(.444)$ & $(.422)$ & $(.434)$ & $(.444)$ & $(.735)$ \\
\hline-2 log likelihood & 72 & 98 & 104 & 100 & 58 \\
\hline Model $\chi^{2}$ & 32 & 30 & 26 & 27 & 34 \\
\hline Pseudo R² & .643 & .532 & .486 & 507 & .711 \\
\hline$N$ & 33 & 43 & 41 & 40 & 30 \\
\hline
\end{tabular}


Use of library reserve was detected to be positively and significantly related to the need for information for solving academic problems. Those who used library reserve more were more likely than their counterparts to respond that they needed information for solving academic problems. It might imply that they could use the reserved textbooks, tapes, and other materials to complete the assignments and projects well.

The predictor of use of ready reference was detected to be negatively and significantly related with the need for information for solving academic problems and software applications usage. Those who utilized ready reference more were less likely to respond that they needed information for solving academic problems and software applications usage. It might imply that their needs were met by making full use of ready reference.

The relationship between the use of online subject guides and information on software applications usage was detected to be positive and significant. Those who used online subject guides more were more likely than their counterparts to respond that they needed information on software applications usage. It suggests that online subject guides might offer them some information on how to use and apply computer software and at the same time they needed more. They might easily obtain available resources to solve academic problems by using subject guides.

A significant and positive relationship between the use of the Internet and the need for information for solving academic problems was detected. Those who browsed the Internet more were more likely than their counterparts to respond that they needed information for solving academic problems. However, the relationships between browsing the Internet and the need for information for improving English proficiency and periodicals in native languages were very significant and negative. Those who browsed the Internet more were less likely than their counterparts to respond that they needed information for improving English proficiency and periodicals in native languages. This suggests that browsing the Internet might help these students improve English proficiency and/or obtain the web sites or links to periodicals in their native languages.

The predictor of the use of email was detected to be significantly and positively related with the need for information for improving English proficiency and periodicals in native languages. Those who used email more were more likely than their counterparts to respond that they needed information for improving English proficiency and periodicals in native languages. However, there was a negative and significant relationship between email use and the need for information for solving academic problems for classes. Those who utilized email more were less likely than their counterparts to respond that they needed information for solving academic problems. These results might suggest that they felt it necessary to improve English, preferred periodicals in their native languages as reference materials in their studies and research, and could get many ways to solve academic problems for classes.

Use of print materials was detected to be positively and significantly related with the need for information for improving library skills. Those who used print materials more were more likely than their counterparts to respond that they 
needed information for improving library skills. However, the relationship between the use of print materials and information on periodicals in native languages was very significant and negative. Those who used print materials more were less likely than their counterparts to respond that they needed information on periodicals in native languages. It may indicate that these students did not have a good mastery of library resources and sources. Thus, librarians or instructors may consider providing library skills trainings and workshops for them. They might find the available print and online periodicals in their native languages which are less needed in the library.

\section{Conclusion}

How does international student library use relate to their information needs? What factors influence their information needs? This study answered these two important research questions. It is an important and useful study that demonstrates the effects of three categories of variables on international student information needs. The practical applications of this study are that directors, managers and librarians can benefit from knowing how demographics, human capital, and library use variables influenced international student information needs, reflect on the factors' influences and use the results to break down international students into smaller groups to satisfy their increasing information needs in the digital age.

Regression results showed that younger students and those using the library computers to send and reply to email more often were more likely than their counterparts to respond on the survey that they had information need for improving English proficiency. However, those who used interlibrary loans more, or browsed the Internet more were less likely to respond that they needed information for improving English proficiency than their counterparts. The more frequently students utilized databases or library reserve, the more likely they were to respond that they needed information for solving academic problems for classes.

Those who used e-journals, ready reference, or email services more were less likely than their counterparts to respond that they needed information for solving academic problems for classes. Students who used print materials more were more likely to respond that they needed information for improving library skills.

Graduate students and those who used online subject guides were more likely than their counterparts to respond that they needed information concerning software application usage. However, those who were younger or utilized e-journals or ready reference more were less likely than their counterparts to respond that they needed information concerning software application usage. Those who browsed the Internet more or utilized interlibrary loan or print materials more were less likely than their counterparts to respond that they needed information on periodicals in their native language.

The regression analysis confirms that demographics, human capital, and library use variables play significant roles in predicting international student information needs. Demographic variables such as age, human capital data such as education level, databases, interlibrary loan, e-journals, library reserve, ready reference, online subject guides, browsing the Internet, email and print materials are 
significant predictors of international student information needs, but this study indicates that gender, library catalog, and remote access to the library offerings make no difference.

The main limitations of this study are that data were collected from a small sample of international students at only one university. Accordingly, the results of the study might not be generalized to other universities. Future research will be conducted on the relationships between more types of international student information needs and more library use variables such as social media tools.

\section{References}

Ademodi, O. (2011) Reference service in academic libraries: accommodation of international students. Library Philosophy and Practice. [online] URL: http://www.webpages.uidaho.edu/ mbolin/ademodi.htm [accessed 01.02.13].

Amsberry, D. (2009) Using effective listening skills with international patrons, Reference Services Review 37(1), 10-19.

Australian Bureau of Statistics (2011) International Students. In 4012.0 Australian Social Trends. URL:

http://www.abs.gov.au/ausstats/abs@.nsf/Previousproducts/4102.0Main\%20Featu res20Dec\%202011?opendocument\&tabname $=$ Summary\&prodno $=4102.0 \&$ issue $=$ Dec\%202011\&num=\&view=\#ENROLMENTS [accessed 01.02.13].

Bilal, D. M. (1989) International students' acquisition of library research skills: relationship with their English language proficiency, The Reference Librarian, 10(24), 129-145.

Bostick, S. L. (1992) The development and validation of the Library Anxiety Scale (Doctoral dissertation, Wayne State University, 1992). Dissertation Abstracts International, 53-12, Section A.4116.

Bruce, C., and Hughes, H. (2010) Informed learning: a pedagogical construct attending simultaneously to information use and learning, Library \& Information Science Research, 32, A2-A8.

Carlile, H. (2007) The implications of library anxiety for academic reference services: a review of the literature, Australian Academic \& Research Libraries, 38(2), 129-147.

Dagli, A. (2004) Culture and information needs in web-based learning: an instrumental case study of multilingual graduate students. $\mathrm{PhD}$ dissertation, Florida State University, Florida.

Frank, R. H. and Bernanke, B. S. (2007), Principles of Microeconomics, 3rd ed. New York: McGraw-Hill/Irwin.

Goudy, F. W. and Moushey, E. (1984) Library instruction and foreign students: a survey of opinions and practices among selected libraries, Reference Librarian, 10(3), 215-226. 
Hughes, H. (2010) International students' experiences of university libraries and librarians, Australian Academic and Research Libraries, 41(2), 77-89.

Institute of International Education (2012a) International education exchanges are at all-time high, strengthening economies and societies around the world (Press Release, 13 Nov 2012).

Institute of International Education (2012b) International student enrollment trends, 1949/50-2011/12. In Open Doors Report on International Educational Exchange.

Koenigstein, D. (2012) Alleviating international students' culture shock and anxiety in American academic libraries: welcome, Ahlan Wa Sahlan, Anyeong Hae Sae Yo, Bienvenidos, Huan Ying, Sanu Da Zuwa, Shalom, Swaagat Hai. Library Philosophy and Practice [online]. URL:

http://www.webpages.uidaho.edu/ mbolin/koenigstein.pdf [accessed 01.02.13].

Liu, G., and Winn, D. (2009) Chinese graduate students and the Canadian academic library: a user study at the University of Windsor, The Journal of Academic Librarianship, 35(6), 565-573.

Liu, M., and Redfern, B. (1997) Information-seeking behavior of multicultural students: a case study at San Jose State University, College \& Research Libraries, 58(4), 348-354.

Liu, Z. (1993) Difficulties and characteristics of students from developing countries in using American libraries, College \& Research Libraries, 54(1), 2531.

Martin, C. K., Maxey-Harris, C., Graybill, J. O. and Rodacker-Borgens, E. K. (2009). Closing the gap: investigating the search skills of international and us students: an exploratory study. Library Philosophy and Practice, [online], 1-17. URL: http://www.webpages.uidaho.edu/ mbolin/martin-maxeyharris-graybillrodackerborgens.pdf [accessed 01.02.13].

Massachusetts Board of Library Commissioners (1993) A strategic plan for the future of library services in Massachusetts. URL:

http://mblc.state.ma.us/mblc/publications/other/publications/stratplan.php [accessed 01.02.13].

Mehra, B., and Bilal, D. (2007) International students' information needs and use of technology, Proceedings of the American Society for Information Science and Technology, 44(1), 1-8.

Mellon, C. A. (1986) Library anxiety: a grounded theory and its development, College \& Research Libraries, 47, 160-165.

Morrissey, R., and Given, L. M. (2006) International students and the academic library: a case study, The Canadian Journal of Information and Library Science, 30(3/4), 221-239.

$\mathrm{Mu}, \mathrm{C}$. (2007) Marketing academic library resources and information services to international students from Asia, Reference Services Review, 35(4), 571-583. 
Office of Economic Development (2011) Access to education, participation and progression. In Education at a Glance 2011: OECD Indicators.

Onwuegbuzie, A. J., and Jiao, Q. G. (1997) Academic library usage: a comparison of native and non-native English-speaking students, Australian Library Journal, 46(3), 258-269.

Peacock, C. (2009) International Students in America: Current Issues for Higher Education and Academic Libraries. URL:

http://charlenepeacock.files.wordpress.com/2010/09/sampleinternationalstudents.pdf [accessed 01.02.13].

Peters, D. (2010) International students and academic libraries: a survey of issues and annotated bibliography. Lanham: Scarecrow Press.

Puente, M. A., Gray, L. and Agnew, S. (2009) The expanding library wall: outreach to the University of Tennessee's multicultural/international student population, Reference Services Review, 37(1), 30-43.

Sacker, N., Secomb, B. and Hulett, H. (2008) How well do you know your clients? : international students' preferences for learning about library services, Australian Academic \& Research Libraries, 39(1), 38-55.

Safahieh, H. (2007) Information Needs and Information Seeking Behavior of International Students in Malaysia. University of Malaya. [online] URL: http://dspace.fsktm.um.edu.my/bitstream/1812/613/1/Hajar\%20Safahieh\%20\%20Final.pdf [accessed 19.02.14].

Texas Woman's University, Office of Institutional Research and Data Management. (2012) Enrollment by country of origin: fall semesters, 2002 through 2012. In Fact Book, B36-B38: TWU.

Yi, Z. (2007) International student perceptions of information needs and use, The Journal of Academic Librarianship, 33(6), 666-673.

\section{Acknowledgement}

This work was supported by the Research Priority Area fund from School of Information Studies, Charles Sturt University, Australia.

\section{Open access and copyright}

Library and Information Research is an open access journal. A freely available copy of this paper may be downloaded from the journal's website:

http://www.lirgjournal.org.uk

Copyright and associated moral rights in works published in Library and Information Research are retained by the author(s) but this paper may be used freely, with proper attribution, in educational and other non-commercial settings. 